\title{
Solid, Liquid and Gas Waste Management includes Handling of Impacts on the Environment and Society
}

\author{
Akkanur Cakir ${ }^{1}$, Kabake Nazim $^{1}$ \\ ${ }^{1}$ Cyprus International University, Cyprus
}

\begin{abstract}
The discussion talked about handling the environment and society from solid, liquid, and gas waste management. In this paper there are several methods that can be used to treat wastewater, including, Dilution (disposal by dilution). Wastewater is discharged into rivers, lakes or the sea to dilute. In this way the wastewater will undergo natural purification. However, this method can contaminate surface water with pathogenic bacteria, worm larvae and eggs, and other germs in the wastewater. If only this method is applicable, the following conditions must be met, River or lake water may not be used for other purposes.
\end{abstract}

Keywords: Dilution, Pathogenic Bacteria, Wastewater

\section{Introduction}

According to Hossain et.al (2011) waste is waste whose presence at a certain time and place is not desired by the environment because it has no economic value. The level of danger of poisoning caused by waste depends on the type and characteristics of the waste, both in the short and long term. Wastes that contain pollutants will change the quality of the environment, if the environment is not able to restore its condition according to its existing carrying capacity. Therefore, it is necessary to know the nature of the waste and the components of the pollutants contained in the waste. Liquid waste is a combination or mixture of water and pollutants carried by water, either in a dissolved or suspended state, which is wasted from domestic sources (offices, housing and trade) and industrial sources.

\section{Solid Waste Management}

Stated by Misra \& Pandey (2005), in processing solid waste, there are four processes, namely separation, sizing, composting, and waste disposal.

\section{Separation}

Because solid waste consists of different sizes and different material content, it must be separated first, so that the processing equipment is durable. There are three separation systems, namely: Ballistic system is a separation system to obtain uniformity of size / weight / volume. Gravity system is a system of separation based on gravity, for example, the terms of light / floating goods and heavy / sinking goods. Magnetic system is a separation system based on magnetic properties which is magnetic, will stick directly. For example, to separate metal and non-metal alloys (Hoornweg \& Bhada-Tata, 2012).

\section{Arrangement of Measures}

Size arrangement is carried out to obtain a smaller size so that processing becomes easy. 


\section{Composting}

Composting is done for perishable waste / waste, municipal waste, animal waste or manure or factory sludge. For good composting results, solid waste must be separated and equalized in size or volume (Epstein, 2017).

Sewage Disposal (b) The sea as a place to find fish for fishermen. (c) The sea as a place for recreation and ship traffic.

\section{The sea became shallow}

Solid waste containing toxic and dangerous chemical compounds can kill marine life. Disposal on land or land, for disposal on land, it is necessary to select a location which must be considered as follows: (1) The influence of climate, temperature and wind. (2) Soil structure. (3) The distance is far from the settlement. (4) Influence to other sources, plantations, fisheries, livestock, flora or fauna. Choose a location that is really not economical anymore for any purpose.

\section{Liquid Waste Management}

Defined by Rajagopal et.al (2013) wastewater before being released to final disposal must undergo treatment first. To be able to carry out effective wastewater treatment requires a good management plan. Wastewater management can be carried out naturally or with the help of equipment. Natural wastewater treatment is usually carried out with the help of stabilization ponds, while water treatment with the help of equipment is carried out for example in a Waste Water Treatment Plant.

In wastewater treatment, it aims to prevent contamination of household water sources, protect animals and plants that live in water, avoid contaminating surface soils and eliminate breeding grounds for seeds and disease vectors. Whereas the requirements for the waste water management system are that it does not cause contamination of drinking water sources, does not cause surface water pollution, does not cause pollution to flora and fauna that live in water in their daily use, not infested by vectors or insects that cause disease. , do not open and must be closed, not cause odor or odor.

\section{Wastewater Management Methods}

There are several methods that can be used to treat wastewater, including: (a) Dilution (disposal by dilution). Wastewater is discharged into rivers, lakes or the sea to dilute. In this way the wastewater will undergo natural purification. However, this method can contaminate surface water with pathogenic bacteria, worm larvae and eggs, and other germs in the wastewater. If only this method is applicable, the following conditions must be met: River or lake water may not be used for other purposes. The volume of water is sufficient so that the dilution takes place less than 30-40 times3. The water must contain sufficient oxygen. In other words, the water must flow (it must not be stagnant) so that it does not cause an odor (Burian, 2000).

\section{Cesspool}

This cesspool resembles a well but is used for waste water disposal. Made on sandy soil so that waste water easily seeps into the soil. The top is walled so that water does not penetrate. When the ceespool is full ( \pm 60 months), the mud inside can be sucked out or from the original cesspool made in series, so that when one is full, the water will flow to the 
next cesspool. The distance between the cesspool and the clean water well is 45 meters and a minimum of 6 meters from the foundation of the house.

\section{Seepage pit}

Infiltration wells are wells to accommodate wastewater that has undergone processing in another system, for example from aqua privy or septic tanks. In this way, the water only remains to be absorbed into the soil. This infiltration well is made on sandy soil, with a diameter of 1-2.5 meters and a depth of 2.5 meters. The duration of use can reach 6-10 years.

\section{Septic tank}

According to $\mathrm{WHO}$, a septic tank is the best method for treating wastewater even though it is expensive, complicated, and requires a large area of land. The septic tank has 4 parts, including: (a) The decomposition room. In this space, dirty water will be held for 13 days and will be decomposed by bacteria that will produce gas, liquid, and sludge. Gas and liquid will enter the dosing chamber through the pipe. The mud will enter the mud chamber. (b) Mud room, mud room is a place for holding mud. When the chamber is full, the sludge can be pumped out. (c) Dosing chamber, in the dosing chamber there is a McDonald siphon which functions to regulate the speed of water that will be flowed into the infiltration area to make it evenly distributed. (d) The absorption field of this field will absorb the liquid out of the dosing chamber and filter out pathogenic bacteria and other germs. The minimum length of this infiltration area is 10 meters and is made on sandy soil.

\section{Riool system (sewage)}

The riool system holds all dirty water from homes and companies, and sometimes collects dirt from the environment. If it is used to collect rainwater, the riool system is called a combined system, whereas if the rainwater collection tanks are separated, it is called a separated system. In order not to harm other interests, dirty water is channeled to the end of the city, for example to areas of livestock, agriculture or inland fisheries. The dirty water still needs treatment. The processing carried out, among others: (a) Screening, filtering is intended to catch objects floating on the surface of the water. (b) Sedimentation. In this process, the waste water is flowed into a large tub (sand trap) so that the flow becomes slow and the mud and sand settle. (c) Biological processes, this process uses microbes to destroy organic substances in waste both aerobically and anaerobically. (d) Filtered with a sand filter (sand filter). (e) Disinfection Disinfection with chlorine (10kg / 1 million wastewater) to kill pathogenic microbes. (f) Dilution Finally, the waste water is discharged into rivers, lakes or seas so that it is diluted. All these wastewater treatment processes are carried out in a special installation built at the end of the city.

\section{Gas Waste Management}

Air pollution can actually come from waste in the form of gas or particulate matter which is at the bottom with the gas. The following will explain several ways to deal with air pollution by waste gas and the bottom particulate matter with it. Controlling Exhaust Emissions

(1) Exhaust gases such as sulfur oxides, nitrogen oxides, carbon monoxide, and hydrocarbons can be controlled through several methods. Sulfur oxide gas can be removed from the air from fuel combustion by desulphurisation using a wet filter (wet scrubber). (2) The working mechanism of this wet filter will be discussed further in the next discussion, namely regarding 
the method of removing particulate matter, because a wet filter is also used to remove particulate matter. (3) Nitrogen oxide gas can be reduced from the combustion of motor vehicles by lowering the combustion temperature. The production of carbon monoxide and hydrocarbons from motorized vehicle combustion can be reduced by installing a catalytic converter to improve combustion. (4) In addition to the methods mentioned above, exhaust emissions can also be reduced by fuel combustion activities or starting to use alternative fuel sources that produce less exhaust gas which is a pollutant.

Removing particulate matter from exhaust air

\section{Air Filter}

The air filter is intended for those that come out of the chimney or stack, so as not to be released into the environment so that only clean air comes out of the chimney. This installed air filter must be constantly observed (controlled), if it is saturated (already full of ash / dust) it must be replaced immediately with a new one.

The type of air filter used depends on the nature of the exhaust gases that come out of the industrial process, whether a lot of dust, whether it is acidic, or alkaline and so on.

\section{Cyclone Precipitator}

Cyclone separators or cyclone separators are dust / ashes that participate in exhaust gases or air in dusty factory spaces. The working principle of cyclone deposition is the use of centrifugal force from air / exhaust gas that is deliberately exhaled through the edge of the cyclone tube wall so that relatively "heavy" particles will fall down (Parker, 2003)

The size of particles / dust / ash that can be deposited by a cyclone is between $5 \mathrm{u}-40 \mathrm{u}$. The larger the dust size, the faster these particles are deposited.

\section{Wet Filter}

Another name for wet filters is Scrubbers or Wet Collectors. The working principle of a wet filter is to clean dirty air by spraying water from the top of the alt, while dirty air from the bottom of the appliance. When dusty air comes in contact with water, the dust will spray the water down.

To get better results, the working principle of the cyclonic precipitator and the wet filter can also be combined into one. The combination of these two types of working principles results in a dust catcher called.

\section{Gravity System Precipitators}

This settling device is only used to clean dirty air whose particle size is relatively large, about $50 \mathrm{u}$ or more. The way this tool works is very simple, namely by flowing dirty air into the tool which is made in such a way that when there is a sudden change in velocity (speed drop), particles will fall and collect under due to their own gravity (gravity). The rate of settling depends on the dimensions of the tool (Jaworek et.al, 2018)

\section{Electrostatic Precipitator}

By Nichols, \& Oglesby (2000) says that electrostatic precipitators are used to clean air that is dirty in a relatively large amount (volume) and the air impurity is aerosol or water vapor. This tool can clean the air quickly and the air that comes out of this tool is relatively clean. 
This electrostatic precipitator uses direct current (DC) which has a voltage between $25-100$ $\mathrm{kv}$. This settler is in the form of a cylindrical tube where the walls are given a positive charge, while in the middle there is a wire which is the center of the cylinder, parallel to the tube wall, which is given a negative charge. The existence of a large enough voltage difference will cause corona discharges in the area around the center of the cylinder. This causes the dirty air to appear as though it is ionizing. Air impurities become negative ions while clean air becomes positive ions and each of them will go to the corresponding electrode. Dirt which becomes negative ions will be drawn by the tube wall while clean air will be in the middle of the cylinder and then blown out.

\section{Conclusion}

Basically, waste is a kind of waste that comes from disposal and it has an impact on the surrounding environment but now many ways or solutions are found to deal with the impacts generated by waste, even though in reality these methods or solutions have no result because there are still many We also encounter waste or rubbish in rivers and land which can also cause flooding and other environmental damage

\section{References}

Burian, S. J., Nix, S. J., Pitt, R. E., \& Durrans, S. R. (2000). Urban wastewater management in the United States: Past, present, and future. Journal of Urban Technology, 7(3), 3362.

Epstein, E. (2017). The science of composting. CRC press.

Hoornweg, D., \& Bhada-Tata, P. (2012). What a waste: a global review of solid waste management.

Hossain, M. S., Santhanam, A., Norulaini, N. N., \& Omar, A. M. (2011). Clinical solid waste management practices and its impact on human health and environment-A review. Waste management, 31(4), 754-766.

Jaworek, A., Marchewicz, A., Sobczyk, A. T., Krupa, A., \& Czech, T. (2018). Two-stage electrostatic precipitators for the reduction of PM2. 5 particle emission. Progress in Energy and Combustion Science, 67, 206-233.

Misra, V., \& Pandey, S. D. (2005). Hazardous waste, impact on health and environment for development of better waste management strategies in future in India. Environment international, 31(3), 417-431.

Nichols, G. B., \& Oglesby Jr, S. (2000). U.S. Patent No. 6,063,168. Washington, DC: U.S. Patent and Trademark Office.

Parker, K. (2003). Electrical operation of electrostatic precipitators (No. 41). IET.

Rajagopal, G., Whitt, J. W., Berryman, G. G., Lains, D. H., Ochranek, B. L., Blackwell, G. A., ... \& Ramsey, J. F. (2013). U.S. Patent No. 8,449,839. Washington, DC: U.S. Patent and Trademark Office. 